\title{
Fluorescence Assay of Glucosylceramide Glucosidase Using NBD-Cerebroside
}

\author{
Akira Abe ${ }^{a, b}$, James A. Shayman ${ }^{a}$ and Norman S. Radin $a, b$, *

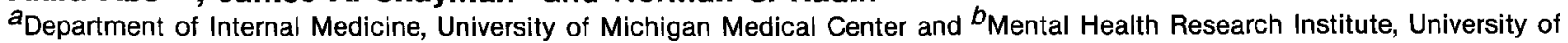 \\ Michigan, Ann Arbor, Michigan 48109-0676
}

A sensitive fluorometric assay for glucocerebroside $\beta$ glucosidase [Dinur, T., Grabowski, G.A., Desnick, R.J., and Gatt, S. (1984) Anal. Biochem. 136, 223-234] has been reexamined. It was found that the lipids containing the NBD moiety (12-[ $N$-methyl- $N$-(7-nitrobenz-2-oxa-1,3-diazol-4-yl)] used for standardization of the assay are light-sensitive and that the yield of fluorescent light is very sensitive to the composition of the solvent used in the fluorometric measurement. Some protection against fading could be obtained by adding a free-radical trapping agent, Slow Fade. The fading of the free NBD-acid, when used for standardization, could be prevented by adding ethanol to the solvent, but this reduced the fluorescence yield. It is recommended that some of the fluorescent substrate be enzymatically hydrolyzed completely to NBD-ceramide, which can be utilized as the standard without the need to add ethanol. A warning about enzyme reaction rate stability with time is given, with a suggestion for ensuring constancy of activity.

Lipids 27, 1052-1054 (1992).

A simple, sensitive and useful method for the assay of glucosylceramide $\beta$-glucosidase (EC 2.3.2.45) has been described $(1,2)$, in which a fluorescent analog of glucosylceramide (NBD-GlcCer) is used as the substrate and the fluorescent enzyme product (NBD-ceramide) is separated from the substrate by liquid/liquid partitioning. While other useful methods are also available, this one has the advantages of simplicity, commercial availability of the substrate and elimination of the need for radioactivity. However, there is a problem in converting the fluorescence readings to molar amounts, since the substrate is not soluble in the solvent used for reading. The authors (2) suggest that a standard solution of NBD-ceramide or NBD-dodecanoic acid be used instead.

Two solvent partitioning steps are used to isolate the product of enzyme action. The first involves the incubation mix ture $(0.45 \mathrm{~mL}$ of water), $0.45 \mathrm{~mL}$ of isopropyl alcohol, and $1.5 \mathrm{~mL}$ of heptane. NBD-ceramide enters the upper phase, together with a little of the substrate; the latter is removed by transferring most of the upper phase, possibly $1.4 \mathrm{~mL}$, and partitioning it against $0.35 \mathrm{~mL}$ of water. The first upper phase (called "theoretical upper phase", TUP) differs in composition from the second, final upper phase (FUP).

The earlier authors (2) calculated the amount of enzymatically-formed ceramide by measuring the fluorescence of a known amount of NBD-ceramide or NBD-acid in the first upper phase, although FUP is the solvent actually used in the fluorometric measurement. The statement is

\footnotetext{
*To whom correspondence should be addressed at Division of Nephrology, University of Michigan, 1150 W. Medical Center Drive, Ann Arbor, MI 48109-0676.

Abbreviations: FUP, final upper phase; GlcCer, glucosylceramide; NBD-acid, 12-[ $N$-methyl- $N$-(7-nitrobenz-2-oxa-1,3-diazol-4-yl)]aminododecanoic acid; NBD-GlcCer, the cerebroside made by acylating glucosylsphingosine with NBD-acid; TUP, theoretical upper phase.
}

made that the two compounds yield the same molar fluorescence values.

No comment was offered about the possible bleaching by light of the NBD compounds during handling and reading, although fluorescent compounds are notorious for fading under some conditions.

In our utilization of the NBD method, we found some discrepancies that led us to investigate the method in more detail. This note describes changes in the procedure that improve the reliability of the method.

\section{MATERIALS AND METHODS}

NBD-GlcCer, NBD-dodecanoic acid, mixed ceramides (Type III) from brain sphingomyelin, and Na taurocholate were from Sigma Chemical Co. (St. Louis, MO). SlowFade was from Molecular Probes, Eugene, OR (gift of Elizabeth Marcus). GlcCer was prepared from a Gaucher spleen (3).

Homogenized Madin-Darby canine kidney cells were used as the glucosidase source. The substrate emulsion in Triton X-100 + Na taurocholate and the incubation mixture were prepared as described (2), and the resultant fluorescent ceramide was assayed as described in a 1-mL cuvet in a Perkin-Elmer (Norwalk, CT) Luminescence Spectrometer LS-5B, with excitation at $460 \mathrm{~nm}$ and emission at $515 \mathrm{~nm}$. A relatively large batch of NBD-ceramide was prepared by scaling up the standard incubation and partitioning procedures, using a 20 -h incubation at $37^{\circ} \mathrm{C}$ to hydrolyze all of the substrate.

By similar scaling up, TUP was prepared with water, isopropyl alcohol and heptane (15:15:50, vol/vol/vol) in a separatory funnel. FUP was prepared from the upper layer.

\section{RESULTS}

Portions of $2 \mu \mathrm{M}$ NBD-acid in FUP were stored under fluorescent laboratory light for 10, 40 and $70 \mathrm{~min}$, yielding readings of 90,70 and 57 units, respectively. Similar instability was found also with more dilute solutions. Thus it was evident that the acid was unstable in light after final partitioning. When NBD-acid was stored under the same conditions in absolute ethanol-FUP solutions, all the solutions were stable to light even with as little as $10 \%$ ethanol. The wavelengths of maximal excitation and emission in $100 \%$ ethanol were shifted to 475 and $535 \mathrm{~nm}$, and there was a small loss of fluorescence yield (74 units for $2 \mu \mathrm{M}$ acid).

Further study with $190 \mathrm{nM} \mathrm{NBD-acid} \mathrm{in} \mathrm{test} \mathrm{tubes}$ stored 15 to $120 \mathrm{~min}$ in FUP or FUP/EtOH (90:10 vol/vol) showed that the readings with FUP could be brought up to the FUP/EtOH readings by adding the EtOH just before the readings were made. For example, NBD-acid stored in the dark for $15 \mathrm{~min}$ in FUP yielded 19 units, stored in FUP/EtOH they yielded 56 units and the addition of EtOH to FUP solutions yielded 55 units. Under these conditions, it appears that the NBD-acid solution, if used as a standard, should contain ethanol. 
The fluorometric readings, with $462 / 523 \mathrm{~nm}$ settings in the fluorometer and NBD-acid in FUP/EtOH (90:10), were proportional to concentration between 25 and $400 \mathrm{nM}$, with the extrapolated line passing through the origin. At the $400 \mathrm{nM}$ level, omitting the ethanol yielded a reading $78 \%$ lower.

Study of $100 \mathrm{nM}$ NBD-ceramide in FUP or FUP/EtOH showed a somewhat different relationship. The ceramide in FUP, read at $515 \mathrm{~nm}$, yielded 96.5, 101.5 and 103.5 fluorescence units after 15, 60 and $120 \mathrm{~min}$ of exposure to ambient fluorescent light, respectively. However, in FUP/EtOH (90:10, vol/vol), read at $523 \mathrm{~nm}$, ceramide yielded much lower values: $38.1,39.8$ and 40.0 units for the same time periods. Thus, while ethanol stabilized the readings over time here too, it quenched the fluorescence from ceramide. Both solvents yielded readings that were proportional to ceramide concentration between 50 and $250 \mathrm{nM}$.

SlowFade, a proprietary free-radical scavenger solution, was tested to see if it exerted a stabilizing action. The reagent was included in the aqueous phase, using $5.6 \%$ of the total water, and the first upper phase was then prepared by adding heptane and isopropyl alcohol. FUP was prepared from this TUP and a 1-mL portion of each solution was added to $190 \mathrm{pmol}$ of NBD-ceramide or acid. The readings, made after $30 \mathrm{~min}$ storage in ambient light (Table 1), showed, first, that there was a great difference in fluorescence when the two upper phases were compared, especially with NBD-ceramide. Second, the two fluorescent compounds responded differently to the two solvents. Third, SlowFade was only slightly useful in the case of ceramide (11\% more fluorescence). Inclusion of SlowFade in the incubation system interfered with glucosidase activity.

The difference between the two fluorescent compounds with regard to the effect of the second partitioning step (decreased fluorescence with the acid $v s$. increased fluorescence with ceramide) is probably due to dimerization of the acid in the less polar FUP, and consequent self-quenching.

A point which does not seem to have been considered before is the possibility that the fluorescent yields might be affected by the detergents in the enzyme incubation solutions. We prepared TUP and FUP using an equeous system similar to the enzyme medium (Triton X-100 and $\mathrm{Na}$ taurocholate in phosphate-citrate buffer), as well as plain water. Results similar to those in Table 1 were obtained, and the detergents were found to make no significant difference in the readings with NBD-ceramide or NBD-acid. In this experiment, a slight amount of selfquenching was found with $250 \mathrm{nM}$ ceramide and much more with the acid (i.e., the reading with $250 \mathrm{nM}$ NBDacid in FUP was only 2.3 times the reading with $50 \mathrm{nM}$ acid).

Another question needing study was the possibility that the presence of ceramide in the incubation system (due to enzyme action) affects the partition constant of the still-unhydrolyzed GlcCer. A test with the standard assay mixture (2), containing NBD-GlcCer and nonfluorescent GlcCer, was compared with the same mixture containing also $5 \mu \mathrm{g}$ of ceramide. The readings obtained in the resultant FUP were very low and similar in the two samples. Evidently the two lipids do not form an extractable complex under these conditions.

\section{TABLE 1}

Effect of an Anti-Fade Reagent on the Fluorescence of NBD Lipids in the Upper Phases Obtained by the Two Partitioning Steps in NBD-Ceramide Isolation ${ }^{a}$

\begin{tabular}{|c|c|c|c|c|}
\hline \multirow{3}{*}{$\begin{array}{l}\text { Solvent } \\
\text { SlowFade present }\end{array}$} & \multicolumn{4}{|c|}{ Fluorescence intensity at $515 \mathrm{~nm}$} \\
\hline & \multicolumn{2}{|c|}{ NBD-ceramide } & \multicolumn{2}{|c|}{$\begin{array}{l}\text { NBD-dodecanoic } \\
\text { acid }\end{array}$} \\
\hline & No & Yes & No & Yes \\
\hline Firs & 88 & 100 & 75 & 75 \\
\hline
\end{tabular}

$a_{\text {The values shown are the means of duplicates. }}$

\section{DISCUSSION}

In view of the difficulty of making an accurate comparison between free NBD-acid and NBD-ceramide molar light yields, and the incomplete constancy of the fluorescence/ concentration ratio of the acid, it is preferable to use the ceramide as the standard. Because of the high cost of the ceramide, and since only a small amount of NBD-ceramide is needed to standardize each set of assays, it is much more economical to make it enzymatically from the substrate. $\beta$ Glucosidase, in the form of crude lysosomes, is readily prepared from any tissue by differential centrifugation. We incubated NBD-GlcCer at $37^{\circ} \mathrm{C}$ overnight in the standard incubation medium (2) and then isolated the product by partitioning in the usual way between heptane, isopropyl alcohol, and water. It is not necessary to purify the NBD-ceramide further since the background fluorescence from the reagents and enzyme is negligible. A thin-layer chromatogram of the material in the FUP, with a silica gel plate and chloroform/HOAc (90:10, vol/vol), examined under ultraviolet light, showed virtually complete conversion of the substrate, with just a trace of free NBD-acid. The concentrations of stock substrate and product solutions were determined by measuring at $\lambda=475 \mathrm{~nm}$, rather than at 485 .

In summary, our recommended changes in the procedure are (i) to make and use NBD-ceramide as the molar standard rather than NBD-acid, (ii) to standardize the assay with NBD-ceramide in FUP, not in TUP, and (iii) to handle the samples in reduced light as much as possible. Moreover, the sensitivity of the fluorescence yield to solvent composition emphasizes the need to do the partitioning and upper phase transfer with maximal reproducibility, preferably with a suction transfer device.

A weakness in the published method (2) is that the reaction rate, using human granulocyte extracts, was not constant over time. The initial rate was relatively high, then it slowed down and became constant after the first $30 \mathrm{~min}$. This makes it difficult to calculate $K_{m}$ and $V_{\max }$ values accurately. While it might be satisfactory to use short incubation times, when the linearity problem is not so severe, this weakens the sensitivity of the assay, since much higher readings can be obtained at the cost only of some patience. Another approach, also unsatisfactory, is to double the number of assay tubes and measure the amount of ceramide formed at the $30-\mathrm{min}$ point and at a somewhat later point.

Perhaps an explanation for the changing velocities lies in a report that the human spleen contains two different GlcCer glucosidases (4). Later study (5) showed that one 
form could be converted into the other, so it is posssible that the conversion occurs during incubation and that the final equilibrium mixture of enzymes is less active than its initial mixture. An early study in the laboratory of the senior author (NSR) yielded a very similar biphasic velocity activity curve with $\beta$-glucosidase from human placenta; preincubation with taurocholate eliminated the first velocity phase (6). Thus systems showing a biphasic time course should be tested with a preincubation protocol.

A study of the literature discloses several papers that give $K_{m}$ and $V_{\max }$ values for this enzyme but very few of these make the claim that the reaction velocity was constant. Using Madin-Darby canine kidney cells, we found the rate was constant over time at all time points studied (5 to $60 \mathrm{~min}$ ) with a $\mathrm{K}_{\mathrm{m}}$ of $0.20 \mathrm{mM}$. Similar constancy was reported for porcine epidermis (7), mouse kidney (8), and purified enzyme from ox brain (9). Glucosidase from human tissues was said to yield constant activities in the case of placenta (10) and, for at least $60 \mathrm{~min}$, with spleen membranes (11), and for $6 \mathrm{~h}$ with skin fibroblasts (12). At present, we can only urge investigators measuring $\beta$ glucosidase to check their velocity constancy.

\section{ACKNOWLEDGMENTS}

This work was supported by a grant from the Mental Health Research Institute, University of Michigan, and from a Merit Review grant of the Department of Veterans Affairs. N.S. Radin is a recipient of the Sen. Jacob Javits Neuroscience Investigator award.

\section{REFERENCES}

1. Grabowski, G.A., Dinur, T., Gatt, S., and Desnick, R.J. (1984) Clin. Chim. Acta 124, 123-135.

2. Dinur, T., Grabowski, G.A., Desnick, R.J., and Gatt, S. (1984) Anal. Biochem. 136, 223-234.

3. Radin, N.S. (1976) J. Lipid Res. 17, 290-293.

4. Aerts, J.M.F.G., Donker-Koopman, W.E., Van Der Vliet, M.K., Jonsson, L.M.V., Ginns, E.I., Murray, G.J., Barranger, J.A., Tager, J.M., and Schram, A.W. (1985) Eur. J. Biochem. 150, 565-574.

5. Aerts, J.M.F.G., Donker-Koopman, W.E., van Laar, C., Brul, S., Murray, G.J., Wenger, D.A., Barranger, J.A., Tager, J.M., and Schram, A.W. (1987) Eur. J. Biochem. 163, 583-589.

6. Radin, N.S. (1975) in Advances in Neurochemistry (Agranoff, B.W., and Aprison, M.H., eds.), pp. 51-94, Plenum Publishing Corp., New York.

7. Wertz, P.W., and Downing, D.T. (1989) Biochim. Biophys. Acta $1001,115-119$.

8. Shukla, G., Shukla, A., Inokuchi, J., and Radin, N.S. (1991) Biochim. Biophys. Acta 1083, 101-108.

9. Gatt, S. (1966) Biochem. J. 101, 687-691.

10. Strasberg, P.M., Lowden, J.A., and Mahuran, D. (1982) Can. J. Biochem. 60, 1025-1031.

11. Glew, R.H., Cristopher, A.R., and Schnure, F.W. (1974) Arch Biochem. Biophys. 160, 162-167.

12. Choy, F.Y.M., and Davidson, R.G. (1980) Am. J. Hum. Genet. 32, 670-680.

[Received April 20, 1992, and in revised form August 11, 1992, Revision accepted September 23, 1992] 